\title{
VIEWPOINT
}

\section{A balanced view of balanced solutions}

\author{
Bertrand Guidett,2,3* , Neil Soni ${ }^{4,5}$, Giorgio Della Rocca ${ }^{6}$, Sibylle Kozek7, Benoît Vallet ${ }^{8}$, Djillali Annane ${ }^{9}$ and Mike James ${ }^{10}$
}

\begin{abstract}
The present review of fluid therapy studies using balanced solutions versus isotonic saline fluids (both crystalloids and colloids) aims to address recent controversy in this topic. The change to the acid-base equilibrium based on fluid selection is described. Key terms such as dilutional-hyperchloraemic acidosis (correctly used instead of dilutional acidosis or hyperchloraemic metabolic acidosis to account for both the Henderson-Hasselbalch and Stewart equations), isotonic saline and balanced solutions are defined. The review concludes that dilutionalhyperchloraemic acidosis is a side effect, mainly observed after the administration of large volumes of isotonic saline as a crystalloid. Its effect is moderate and relatively transient, and is minimised by limiting crystalloid administration through the use of colloids (in any carrier). Convincing evidence for clinically relevant adverse effects of dilutional-hyperchloraemic acidosis on renal function, coagulation, blood loss, the need for transfusion, gastrointestinal function or mortality cannot be found. In view of the longterm use of isotonic saline either as a crystalloid or as a colloid carrier, the paucity of data documenting detrimental effects of dilutional-hyperchloraemic acidosis and the limited published information on the effects of balanced solutions on outcome, we cannot currently recommend changing fluid therapy to the use of a balanced colloid preparation.
\end{abstract}

\section{Introduction}

Normal saline solution has been used for over 50 years in a multitude of clinical situations as an intraoperative, resuscitation and maintenance fluid therapy. Neither normal nor physiological, however, saline solution is still a standard against which other solutions are measured.

*Correspondence: bertrand.guidet@sat.aphp.fr

${ }^{3}$ Medical ICU, Assistance Publique - Hôpitaux de Paris, Hôpital Saint-Antoine,

Service de Réanimation Médicale, Paris F-75012, France

Full list of author information is available at the end of the article
Much attention has been given recently to so-called balanced solutions such as Ringer's lactate, and more recent derivatives. Colloids prepared in balanced electrolyte solutions have also been developed, alongside colloids in isotonic saline.

As one might expect, excessive use of saline has been observed to result in hyperchloraemic acidosis - which has been identified as a potential side effect of salinebased solutions. There is debate about the morbidity associated with this condition, although some consider the associated morbidity is probably low. It has been suggested that the use of balanced solutions may avoid this effect.

This acidosis effect was reviewed and highlighted in the British Consensus Guidelines on Intravenous Fluid Therapy for Adult Surgical Patients [1]. These guidelines clearly recommend the use of balanced crystalloids rather than saline - but they make no specific recommendations regarding colloids, implying that they could be either standard or balanced. The publication of these guidelines has provoked strong reactions. In a British Medical Journal editorial, Liu and Finfer comment: 'Although administration of normal saline can cause hyperchloraemic acidosis, we do not know whether this is harmful to patients. Adopting this guideline is unlikely to harm patients, but may not have any tangible benefit' [2].

Others have reviewed the physiological effects of acidosis. Handy and Soni noted that 'There is little evidence that in 50 years of normal saline usage, there has been significant morbidity from the use of this fluid' [3]. Liu and Finfer continue: 'The danger in providing consensus guidelines endorsed by specialist societies is that clinicians may feel pressured to adopt interventions that may, in the longer term, be found to cost more and to do more harm than good. We agree with the recently expressed view that unless recommendations are based on high quality primary research, then perhaps guidelines should be avoided completely, and clinicians would be better off making clinical decisions on the basis of primary data' [4].

Given the obvious controversy that exists based on the interpretation of the available information, the entire topic should clearly be reviewed again. Accordingly, the present article reviews the available literature comparing 
balanced solutions with isotonic saline fluids (both crystalloids and colloids) and investigates the scientific basis that should be taken into account in any future guidelines or recommendations.

\section{The acid-base equilibrium: Henderson-Hasselbalch versus Stewart}

It is vital to determine the mechanism for an acid-base disturbance in critically ill patients in order to administer appropriate treatment. The Henderson-Hasselbalch equation is still the standard method for interpreting acid-base equilibrium in clinical practice [5]:

$$
\mathrm{pH}=\mathrm{pK}_{1}{ }^{\prime}+\log \left[\mathrm{HCO}_{3}^{-}\right] /\left(S \times \mathrm{PCO}_{2}\right)
$$

This equation describes how plasma $\mathrm{CO}_{2}$ tension, plasma bicarbonate $\left(\mathrm{HCO}_{3}^{-}\right)$concentration, the apparent dissociation constant for plasma carbonic acid $(\mathrm{pK})$ and the solubility of $\mathrm{CO}_{2}$ in plasma interact to determine plasma $\mathrm{pH}$. The magnitude of the metabolic acidosis is generally quantified by the base deficit or base excess, which is defined as the amount of base (or acid) that must be added to a litre of blood to return the $\mathrm{pH}$ to 7.4 at a partial pressure of carbon dioxide $\left(\mathrm{PCO}_{2}\right)$ of $40 \mathrm{mmHg}$. The main consequence of infusion of isotonic saline is a dilution of bicarbonate. The dilution of albumin may also play a minor role. Accordingly, the observed disorder is reported as a dilutional acidosis, associating a base deficit with a high chloride concentration.

A different approach (the strong ion approach) to acidbase equilibrium was developed in 1983 by Stewart to account for fluctuation of the variables that independently regulate plasma $\mathrm{pH}[6]$. He proposed that plasma $\mathrm{pH}$ is affected by three independent factors: $\mathrm{PCO}_{2}$; the strong ion difference (SID), which is the difference between the charge of plasma strong cations (sodium, potassium, magnesium and calcium) and strong anions (chloride, sulphate, lactate and others); and the sum of all anionic charges of weak plasma acids $\left(\mathrm{A}_{\text {tot }}\right)$, which is the total plasma concentration of nonvolatile buffers (albumin, globulins, phosphate). More advanced explanations are available in a recent review by Yunos and colleagues [7]. The Stewart equation may be written in a similar form to the Henderson-Hasselbalch equation [8]:

$$
\mathrm{pH}=\mathrm{pK}_{1}{ }^{\prime}+\log \left[\mathrm{SID}-\mathrm{A}_{\mathrm{tot}} /\left(1+10^{\mathrm{pKa}-\mathrm{pH}}\right)\right] /\left(S \times \mathrm{PCO}_{2}\right)
$$

At the usual $\mathrm{pH}$ of plasma, part of the albumin complex carries a negative charge, which could therefore play a role in buffering $\mathrm{H}^{+}$ions. The same applies to phosphate, although the concentration of phosphate in the plasma is too low to provide significant buffering. Accordingly, the Stewart approach emphasises the role of albumin, phosphate and other buffers in acid-base equilibrium.
The Stewart approach can distinguish six primary acidbase disturbances instead of the four differentiated by the Henderson-Hasselbalch equation. This strong ion approach also provides a more comprehensive explanation of the role of chloride in acid-base equilibrium.

The SID of isotonic saline being 0 , the infusion of large quantities will dilute the normal SID of plasma and decrease $\mathrm{pH}$. Hyperchloraemic metabolic acidosis is therefore a decrease in SID associated with an increase in chloride. The Stewart equation also shows that the infusion of isotonic saline will also dilute albumin and decrease $\mathrm{A}_{\text {tot }}$, which tends to increase $\mathrm{pH}$. Using the Stewart equation, a balanced solution with a physiological SID of $40 \mathrm{mEq} / \mathrm{l}$ would induce a metabolic alkalosis. Morgan and Venkatesh have calculated that a balanced solution should have a SID of $24 \mathrm{mEq} / \mathrm{l}$ in order to avoid this induction [9]. It should be noted that balanced solutions using organic anions (such as lactate, acetate, gluconate, pyruvate or malate) have an in vitro SID equal to 0 , similar to isotonic saline. In vivo, the metabolism of these anions increases the SID and also decreases the osmolarity of the solution.

This equation, while comprehensive, is still complex for common use if used in its entirety, but a simplified Stewart approach can be used to make a graphical interpretation of the acid-base equilibrium. This approach takes into account the effects of the most important substances affecting equilibrium: sodium, potassium, calcium and magnesium minus chloride and lactate. In this approach, the apparent SID is defined as follows (see Figure 1):

$$
\text { Apparent SID }=\left(\left[\mathrm{Na}^{+}\right]+\left[\mathrm{K}^{+}\right]\right)-\left(\left[\mathrm{Cl}^{-}\right]+[\text {lactate }]\right)
$$

The two acid-base equilibrium approaches are mathematically equivalent but are completely different from a conceptual point of view. Both are subject to criticism. The Stewart approach has been criticised for incorporating bicarbonate as a dependent variable, the result of a calculation, while it is obvious that physiologically bicarbonate plays a central role and is regulated mainly by the kidneys. Conversely, the Henderson-Hasselbalch approach is centred on bicarbonate, which may reflect the physiological reality better. In the dilution concept, metabolic acidosis following resuscitation with large volumes of isotonic saline is attributed to dilution of serum bicarbonate. The Stewart approach rejects this explanation, however, and offers an alternative that is based on a decrease in SID. This mechanistic explanation is questioned by several authors for fundamental chemical reasons $[10,11]$. If correct, the Stewart approach is valid at the mathematical level but does not provide mechanistic insights. The quantification and categorisation of acid-base disorders using the Stewart approach, 


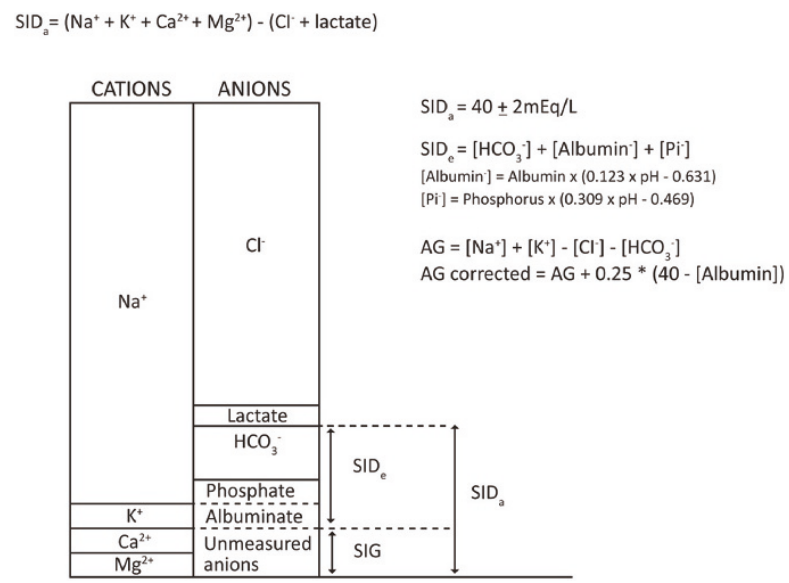

Figure 1. Representation of the Stewart model. Charge balance in blood plasma. Any difference between apparent strong ion difference (SID) and effective strong ion difference $\left(S_{2} D_{e}\right)$ is the strong ion gap ( $\mathrm{SIG}$ ) and presents unmeasured anions. The SIG should not be confused with the anion gap (AG). A corrected AG can be calculated to account for variations in albumin concentration. Adapted from Stewart [6].

however, may be helpful in clinical practice to understand some complex disorders.

The intra-erythrocyte and interstitial space buffers are not taken into account in either approach. These buffers play a major role in acid-base equilibrium and must be included, particularly in the case of isotonic saline administration [12] (Figure 2).

The most important consideration is the cause of the acidosis. Acidosis is often the consequence of a physiological disturbance or an iatrogenic event. The difficulty lies in separating the effects of the pathophysiology driving the acidosis. For example, metabolic acidosis can be a sign of organ distress due to hypoperfusion or hypoxia (for example, shock, ketoacidosis or kidney disease) [3]. This will produce profound physiological effects that are all readily ascribed to the acidosis rather than to its cause. Correction of the pathology may correct the acidosis, but correction of the acidosis solely is unlikely to affect the pathology. Therefore it is important to understand the mechanism causing the acidosis.

\section{Definitions}

In the present article, in an attempt to better describe disorders and solutions, we have used the following terms.

\section{Dilutional-hyperchloraemic acidosis}

The term dilutional-hyperchloraemic acidosis is used instead of dilutional acidosis or hyperchloraemic metabolic acidosis, in order to reconcile both theories (Henderson-Hasselbalch and Stewart). In reality, many

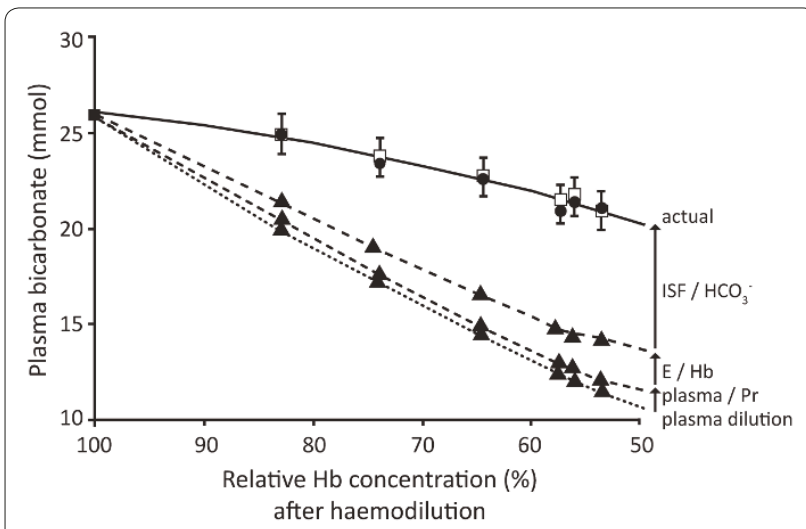

Figure 2. Plasma bicarbonate concentration versus relative haemoglobin after acute haemodilution in different patient groups. Plasma bicarbonate $\left(\mathrm{HCO}_{3}^{-}\right)$concentration ( $\left.\mathrm{mmol} / \mathrm{l}\right)$ versus relative haemoglobin $(\mathrm{Hb})(\%)$ after acute normovolaemic haemodilution in different patient groups. Comparison is shown for predicted (open squares) and reported (filled circles) values [18] of the actual $\mathrm{HCO}_{3}{ }^{-}$concentration (top curve), composed of the calculated $\mathrm{HCO}_{3}{ }^{-}$values (filled triangles) from plasma dilution, plus the increments from the plasma proteins (Pr), the erythrocytes (E), and the interstitial fluid (ISF) with corresponding buffers. Adapted from Lang and Zander [12].

articles on hyperchloraemic metabolic acidosis do not report SID changes and only mention base excess variations and chloride concentrations.

\section{Isotonic saline}

Isotonic saline describes the main property of $0.9 \%$ saline solution. The solution is neither normal, abnormal nor unbalanced. Sodium and chloride are partially active, the osmotic coefficient being 0.926 . The actual osmolality of $0.9 \%$ saline is $287 \mathrm{mOsm} / \mathrm{kg} \mathrm{H}_{2} \mathrm{O}$, which is exactly the same as the plasma osmolality.

\section{Balanced solutions}

Used generally to describe different solutions with different electrolyte compositions close to plasma composition, balanced solutions are neither physiological nor plasmaadapted. Table 1 presents the electrolyte composition of commonly available crystalloids. Table 2 presents the electrolyte composition of commonly used colloids.

\section{Quantitative effects of isotonic saline infusion on acid-base equilibrium}

The effects of isotonic saline infusion are illustrated by Rehm and Finsterer in patients awaiting intra-abdominal surgery [13]. Patients received $40 \mathrm{ml} / \mathrm{kg} /$ hour of $0.9 \%$ isotonic saline, a total of 6 litres isotonic saline in 2 hours. The apparent SID decreased from 40 to $31 \mathrm{mEq} / \mathrm{l}$, chloride significantly increased from 105 to $115 \mathrm{mmol} / \mathrm{l}$ and a decrease in base excess of approximately $7 \mathrm{mmol} / \mathrm{l}$ was observed. These data perfectly illustrate 
Table 1. Electrolyte composition ( $\mathrm{mmol} / \mathrm{l}$ ) of commonly available crystalloids

\begin{tabular}{|c|c|c|c|c|c|}
\hline Electrolyte & Plasma & $0.9 \% \mathrm{NaCl}$ & Ringer's lactate, Hartmann's & Plasma-Lyte & Sterofundin ${ }^{\circ}$ \\
\hline Sodium & 140 & 154 & 131 & 140 & 140 \\
\hline Potassium & 5 & 0 & 5 & 5 & 4 \\
\hline Chloride & 100 & 154 & 111 & 98 & 127 \\
\hline Calcium & 2.2 & 0 & 2 & 0 & 2.5 \\
\hline Magnesium & 1 & 0 & 1 & 1.5 & 1 \\
\hline Bicarbonate & 24 & 0 & 0 & 0 & 0 \\
\hline Lactate & 1 & 0 & 29 & 0 & 0 \\
\hline Acetate & 0 & 0 & 0 & 27 & 24 \\
\hline Gluconate & 0 & 0 & 0 & 23 & 0 \\
\hline Maleate & 0 & 0 & 0 & 0 & 5 \\
\hline
\end{tabular}

Plasma-Lyte from Baxter International (Deerfield, IL, USA). Sterofundin from B Braun (Melsungen, Germany).

Table 2. Electrolyte composition (mmol/l) of commonly available colloids

\begin{tabular}{|c|c|c|c|c|c|c|c|c|c|}
\hline & $\begin{array}{c}\text { Albumin } \\
4 \%\end{array}$ & $\begin{array}{c}\text { Plasmion }^{\circledR} \\
\text { Geloplasma }^{\circledR}\end{array}$ & Gelofusine ${ }^{\circledR}$ & $\begin{array}{c}\text { Voluven }^{\circledR} \\
\text { (waxy maize } \\
\text { HES 6\% } \\
130 / 0.40 \text { ) }\end{array}$ & $\begin{array}{c}\text { Venofundin }{ }^{\circledR} \\
\text { (potato } \\
\text { HES 6\% } \\
130 / 0.42 \text { ) }\end{array}$ & $\begin{array}{c}\text { Hextend }^{\circledR} \\
\text { (waxy maize } \\
\text { HES 6\% } \\
670 / 0.75 \text { ) }\end{array}$ & $\begin{array}{c}\text { Volulyte }^{\circledR} \\
\text { (waxy maize } \\
\text { HES 6\% } \\
130 / 0.40 \text { ) }\end{array}$ & $\begin{array}{c}\text { PlasmaVolume }^{\circledR} \\
\text { (potato } \\
\text { HES } 6 \% \\
130 / 0.42 \text { ) }\end{array}$ & $\begin{array}{c}\text { Tetraspan }^{\circledR} \\
\text { (potato } \\
\text { HES 6\% } \\
130 / 0.42 \text { ) }\end{array}$ \\
\hline Sodium & 140 & 150 & 154 & 154 & 154 & 143 & 137 & 130 & 140 \\
\hline Potassium & 0 & 5 & 0 & 0 & 0 & 3 & 4 & 5.4 & 4.0 \\
\hline Chloride & 128 & 100 & 125 & 154 & 154 & 124 & 110 & 112 & 118 \\
\hline Calcium & 0 & 0 & 0 & 0 & 0 & 2.5 & 0 & 0.9 & 2.5 \\
\hline Magnesium & 0 & 1.5 & 0 & 0 & 0 & 0.5 & 1.5 & 1 & 1.0 \\
\hline Bicarbonate & 0 & 0 & 0 & 0 & 0 & 0 & 0 & 0 & 0 \\
\hline Lactate & 0 & 30 & 0 & 0 & 0 & 28 & 0 & 0 & 0 \\
\hline Acetate & 0 & 0 & 0 & 0 & 0 & 0 & 34 & 27 & 24 \\
\hline Octanoate & 6.4 & 0 & 0 & 0 & 0 & 0 & 0 & 0 & 0 \\
\hline
\end{tabular}

HES, hydroxyethyl starch. Gelofusine ${ }^{\oplus}$, Venofundin ${ }^{\circledast}$ and Tetraspan ${ }^{\circledast}$ from B Braun (Melsungen, Germany). Plasmion ${ }^{\circledast}$, Geloplasma ${ }^{\circledast}$, Voluven ${ }^{\circledast}$ and Volulyte ${ }^{\circledast}$ from Fresenius-Kabi (Bad Homburg, Germany). Hextend ${ }^{\circledast}$ from BioTime Inc. (Berkeley, CA, USA). PlasmaVolume ${ }^{\circledast}$ from Baxter International (Deerfield, IL, USA).

dilutional-hyperchloraemic acidosis following infusion of large volumes of isotonic saline in clinical practice. Before determining the clinical relevance of dilutional hyperchloraemic acidosis, it is important to quantify the respective contribution of crystalloids and colloids.

Several studies have reported the biological effects following infusion of crystalloids alone $[14,15]$. Boldt and colleagues provide an interesting illustration of the effects following infusion of very high doses of crystalloid (isotonic saline versus Ringer's lactate) [16]. In patients undergoing major abdominal surgery, they reported the intraoperative infusion of 8 litres of crystalloids, followed by a further 10 litres of postoperative infusion in 48 hours (Table 3), resulting in a total dose of 18 litres of either Ringer's lactate or isotonic saline. As shown in Table 3, these extreme doses of isotonic saline were associated with moderate and transient effects on acid-base equilibrium: a decrease in base excess of $5 \mathrm{mmol} / \mathrm{l}$ that lasted for 1 or 2 days.
A number of studies have also reported and compared the effects following the infusion of large volumes of colloids and crystalloids with isotonic saline or balanced solutions [17-22].

In patients undergoing abdominal surgery, Boldt and colleagues used colloid (HES 130/0.42) either in a balanced solution or in an isotonic saline solution. In this study, a total balanced fluid therapy (colloid and crystalloid) was compared with a total isotonic saline-based strategy [18]. It is interesting to note that, despite the large volumes of fluid used ( $>6$ litres), the difference in chloride concentration was $+8 \mathrm{mmol} / \mathrm{l}$ and the difference in base excess was $-5 \mathrm{mmol} / \mathrm{l}$ between the groups (Table 4). These changes were similar to or lower than those in other studies (Table 4).

O'Dell and colleagues established that there is an inverse linear relationship between chloride load and base excess [23]. According to this relationship, to decrease base excess by $10 \mathrm{mmol} / \mathrm{l}$ in a typical $70 \mathrm{~kg}$ 
Table 3. Total volume input and urine output: effects on chloride and base excess [16]

\begin{tabular}{|c|c|c|c|c|}
\hline & After surgery & 5 hours on ICU & $\begin{array}{c}\text { First } \\
\text { postoperative day }\end{array}$ & $\begin{array}{c}\text { Second } \\
\text { postoperative day (total) }\end{array}$ \\
\hline \multicolumn{5}{|c|}{ Cumulative volume input (ml) } \\
\hline Ringer's lactate & $7,950 \pm 950$ & $9,070 \pm 920$ & $14,150 \pm 1,150$ & $18,750 \pm 1,890$ \\
\hline Saline solution & $8,230 \pm 580$ & $9,550 \pm 880$ & $13,790 \pm 1,650$ & $17,990 \pm 1,790$ \\
\hline \multicolumn{5}{|c|}{ Cumulative urine output (ml) } \\
\hline Ringer's lactate & $1,950 \pm 340$ & $4,400 \pm 410$ & $7,700 \pm 370$ & $11,450 \pm 460$ \\
\hline Saline solution & $2,250 \pm 240$ & $3,920 \pm 350$ & $6,950 \pm 430$ & $12,940 \pm 390$ \\
\hline \multicolumn{5}{|l|}{$\mathrm{Cl}^{-}(\mathrm{mmol} / \mathrm{l})$} \\
\hline Ringer's lactate & $104 \pm 3$ & $105 \pm 3$ & $102 \pm 2$ & $102 \pm 3$ \\
\hline Saline solution & $113 \pm 4^{*+}$ & $111 \pm 3^{*+}$ & $111 \pm 3^{*+}$ & $106 \pm 5$ \\
\hline \multicolumn{5}{|l|}{ Base deficit (mmol/l) } \\
\hline Ringer's lactate & $-0.5 \pm 0.6$ & $-1.0 \pm 1.2$ & $2.0 \pm 0.5$ & $2.9 \pm 1.1$ \\
\hline Saline solution & $-5.6 \pm 2.1^{*+}$ & $-4.2 \pm 1.9^{*+}$ & $-2.8 \pm 1.1^{* \dagger}$ & $0.3 \pm 1.5^{*}$ \\
\hline
\end{tabular}

$\mathrm{ICU}$, intensive care unit. ${ }^{*} P<0.05$ difference compared with the other group. ${ }^{\dagger} P<0.05$ difference compared with baseline values.

patient it would be necessary to infuse $20 \mathrm{mmol} / \mathrm{kg}$ chloride - equivalent to around 9 litres of isotonic saline. Putting this in the context of the normal maximum doses of colloids, infusion of $50 \mathrm{ml} / \mathrm{kg}$ HES 130/0.4 would reduce base excess by a maximum of $3.5 \mathrm{mmol} / \mathrm{l}$, which largely corresponds with observations in published studies. Overall, these studies suggest that when patients are treated with a combination of isotonic saline-based colloids and crystalloids, the effects on acid-base equilibrium are limited.

Base and colleagues used a different fluid strategy in patients undergoing cardiac surgery. HES 130/0.4 was administered either in a balanced solution or a saline solution. The two groups also received the same balanced crystalloid, Ringer's lactate [17]. The chloride concentration at the end of surgery was $110 \mathrm{mmol} / \mathrm{l}$ in the group receiving HES in a balanced solution, compared with $112 \mathrm{mmol} / \mathrm{l}$ in the isotonic saline-based solution. The difference is statistically significant but is not clinically relevant. Base excess decreased in both groups, but the maximum difference between the groups at any time point was around $2 \mathrm{mmol} / \mathrm{l}$.

The respective role of crystalloids and colloids on acidbase equilibrium is perfectly illustrated by Boldt and colleagues in elderly patients undergoing abdominal surgery [24]. Three different strategies were used: Ringer's lactate, isotonic saline, and HES 130/0.4 plus Ringer's lactate. The chloride and sodium loads and the effect on base excess are shown in Figure 3. Although the colloid used in this study was supplied in an isotonic saline carrier, overall the impact on base excess was similar to that of Ringer's lactate alone and remained within the normal range.

Overall, these studies suggest that large volumes of saline will increase the chloride concentration and reduce base excess in a dose-dependent manner, with the peak effect occurring a few hours post infusion. The effect is temporary, and levels generally return to normal within 1 or 2 days. When fluid therapy is based on colloids in an isotonic saline carrier, together with a balanced crystalloid like Ringer's lactate, the effects on acid-base equilibrium appear limited. Owing to a lack of published clinical experience, it remains to be seen whether patients with pre-existing metabolic acidosis are more affected due to a reduced buffering capacity. Transient isotonic saline-induced reduction of base excess should be considered when interpreting the acid-base status in unstable patients.

\section{Is dilutional-hyperchloraemic acidosis clinically relevant?}

While it is clear that dilutional-hyperchloraemic acidosis exists, it is important to examine whether it has any effect on organ function. The kidney, gastrointestinal tract and coagulation system have often been mentioned as possible targets.

\section{Effects of dilutional-hyperchloraemic acidosis on renal function}

Animal studies suggest that chloride may have effects on the kidney including renal vasoconstriction, an increase in renal vascular resistance, a decrease in glomerular filtration rate and a decrease in renin activity [25-28]. At normal and slightly high concentrations, however, the effects are small [29].

Differences in osmolarity between Ringer's lactate and isotonic saline have to be taken into account to understand the effects on renal function and urine output. The osmolarity of Ringer's lactate is $273 \mathrm{mOsm} / \mathrm{l}$. In dilute physiological solutions, the values of osmolality 
Table 4. Effects on base excess and chloride concentrations from different clinical studies

\begin{tabular}{|c|c|c|c|c|c|}
\hline Study & Setting & Infusion strategy & $\begin{array}{c}\text { Volumes } \\
\text { infused during } \\
\text { study period (ml) }\end{array}$ & $\begin{array}{c}\text { Minimal value } \\
\text { in base excess } \\
(\mathrm{mmol} / \mathrm{l})\end{array}$ & $\begin{array}{c}\text { Maximal change } \\
\text { in chloride } \\
\text { (mmol/l) }\end{array}$ \\
\hline \multirow[t]{6}{*}{ Boldt and colleagues [18] } & Abdominal surgery & Balanced group & & $<1^{\mathrm{a}}$ & $+3^{\mathrm{a}}$ \\
\hline & & HES 130/0.42 & $3,866 \pm 1,674$ & & \\
\hline & & Modified RL & $5,966 \pm 1,202$ & & \\
\hline & & Saline-based group & & $-5^{a}$ & $+8^{\mathrm{a}}$ \\
\hline & & HES 130/0.42 & $3,533 \pm 1,302$ & & \\
\hline & & Isotonic saline & $5,333 \pm 1,063$ & & \\
\hline \multirow[t]{6}{*}{ Kulla and colleagues [21] } & Abdominal surgery & Balanced & & -1.8 & +3 \\
\hline & & HES 130/0.42 & $1,923 \pm 989$ & & \\
\hline & & Modified RL & $4,268 \pm 999$ & & \\
\hline & & Saline-based & & -4.2 & +5 \\
\hline & & HES 130/0.42 & $1,828 \pm 522$ & & \\
\hline & & Modified saline & $4,490 \pm 1,126$ & & \\
\hline \multirow[t]{6}{*}{ Boldt and colleagues [19] } & Cardiac surgery & Balanced & & -1.2 & Not reported \\
\hline & & HES 130/0.42 & $2,750 \pm 640$ & & \\
\hline & & Modified RL & $5,200 \pm 610$ & & \\
\hline & & Saline-based & & -4.4 & Not reported \\
\hline & & HES 130 & $2,820 \pm 550$ & & \\
\hline & & Isotonic saline & $5,150 \pm 570$ & & \\
\hline \multirow[t]{6}{*}{ Boldt and colleagues [20] } & Cardiopulmonary bypass & Balanced & & $0^{\mathrm{a}}$ & Not reported \\
\hline & & HES 130/0.42 & $3,090 \pm 540$ & & \\
\hline & & Modified RL & $4,010 \pm 410$ & & \\
\hline & & Saline-based & & $-6^{a}$ & Not reported \\
\hline & & $5 \%$ albumin & $3,110 \pm 450$ & & \\
\hline & & Isotonic saline & $5,450 \pm 560$ & & \\
\hline \multirow[t]{6}{*}{ Boldt and colleagues [22] } & Cardiopulmonary bypass & Balanced & & $-1^{\mathrm{a}}$ & Not reported \\
\hline & & HES 130/0.40 & $2,950 \pm 530$ & & \\
\hline & & Modified RL & $5,090 \pm 750$ & & \\
\hline & & Saline-based & & $-5^{\mathrm{a}}$ & Not reported \\
\hline & & $5 \%$ albumin & $3,050 \pm 560$ & & \\
\hline & & Isotonic saline & $5,050 \pm 680$ & & \\
\hline
\end{tabular}

HES, hydroxyethyl starch; RL, Ringer's lactate. avalues estimated from figures reported in the article.

and osmolarity are interchangeable. In vivo, however, the osmolality of Ringer's lactate is only $254 \mathrm{mOsm} / \mathrm{kg}$. This discrepancy is due to incomplete ionisation of the solutes in Ringer's lactate. On the contrary, isotonic saline, which is completely ionised, has an osmolality similar to the calculated osmolarity of $308 \mathrm{mOsm} / \mathrm{l}$. Compared with the osmolality of normal serum (285 to $295 \mathrm{mOsm} / \mathrm{kg}$ ), therefore, Ringer's lactate is clearly hypotonic while $0.9 \%$ saline is isotonic.

In a study with human volunteers, Williams and colleagues tested the hypothesis that infusion of large volumes of Ringer's lactate or isotonic saline may have different effects on renal function and urine output [15].
There was a significant difference in mean time to urination, Ringer's lactate solution being associated with the shorter time to first urine output. In fact, in the Ringer's lactate group a decrease in serum osmolality probably inhibited the release of antidiuretic hormone. The resulting diuresis of hypotonic urine causes the serum osmolality to return quickly to normal.

These changes in osmolarity must be taken into account in the interpretation of clinical studies comparing Ringer's lactate with isotonic saline. In a similar study by Reid and colleagues, time to first micturition was shorter in the Ringer's lactate group, and was associated with a decreased urine osmolarity [30]. This suggests that the 


\begin{tabular}{|l|c|c|}
\hline Group & $\begin{array}{c}\text { Chloride load in mmol } \\
\text { (\% vs isotonic saline) }\end{array}$ & $\begin{array}{c}\text { Sodium load in mmol } \\
\text { (\% vs isotonic saline) }\end{array}$ \\
\hline Isotonic saline & $1571(100 \%)$ & $1571(100 \%)$ \\
\hline Ringer's Lactate & $1106(70 \%)$ & $1313(84 \%)$ \\
\hline HES 130/0.4 plus Ringer's Lactate & $745(47 \%)$ & $804(51 \%)$ \\
\hline
\end{tabular}

Base Excess (mmol/L)

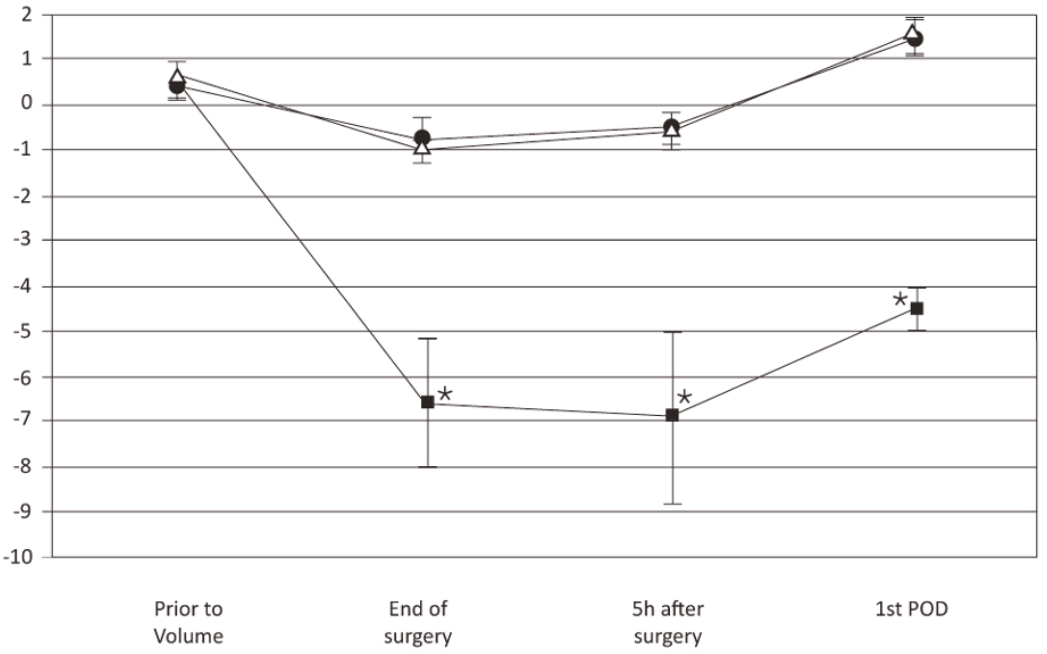

Figure 3. Chloride load and base excess in elderly patients undergoing abdominal surgery. Chloride load in the three groups of patients Ringer's lactate group (filled circles), isotonic saline group (filled squares), and HES 130/0.4 plus Ringer's lactate (open triangles) - was calculated. The variations in base excess for the three groups are shown graphically. It is remarkable that there is no difference between the Ringer's lactate group and the HES 130/0.4 plus Ringer's lactate group. * $P<0.05$. POD, postoperative day. Adapted from Boldt and colleagues [24].

free water clearance adjusted to changes in osmolality. In their study, the isotonic saline group retained a greater proportion of the sodium load than did the Ringer's lactate group, which may account for the difference in fluid retention. These results emphasise that differences in osmolality between balanced solutions and isotonic saline must be taken into account in the interpretation of renal function parameters such as time to micturition and urine output.

O'Malley and colleagues compared Ringer's lactate with isotonic saline in patients undergoing renal transplantation. This study found that recipients undergoing kidney transplants had greater acidosis and higher potassium concentrations if they were given isotonic saline as opposed to Ringer's lactate [31]. These effects are the consequence of acidosis mobilising potassium from the intracellular space in patients where renal function is unable to compensate for these changes. It is worth noting that there was no adverse effect of isotonic saline on renal function. There is no evidence of this effect in other studies comparing isotonic saline with balanced salt crystalloids [31].
Boldt and colleagues published a series of articles in which a totally balanced strategy (balanced crystalloid and balanced colloid) was compared with a standard treatment (isotonic saline and colloid in isotonic saline carrier) (Table 4). In one study, in patients undergoing major abdominal surgery there was no significant difference in urine output and in serum creatinine on the first postoperative day [18].

Another study in elderly patients undergoing cardiac surgery also reported no major impact on renal function [19]. For up to 60 days following surgery, there was no difference between the groups regarding plasma creatinine concentration. Levels of neutrophil gelatinase-associated lipocalin (NGAL) were also measured. There was a small increase on the first day after surgery in the isotonic saline-based group, but levels in both groups were nearnormal by the second day. Overall NGAL values were extremely low (around $20 \mathrm{ng} / \mathrm{ml}$ ), significantly below the threshold of $150 \mathrm{ng} / \mathrm{ml}$ that is considered an indicator of acute kidney injury.

Finally, a study investigating the effects of two colloid strategies in patients undergoing cardiopulmonary 
bypass was also reported by Boldt and colleagues [20]. Albumin in saline carrier was compared with an HESbased colloid in balanced solution. There was no significant difference in serum creatinine following surgery; and although an increase in NGAL of $15 \mathrm{ng} / \mathrm{ml}$ was observed in the albumin group, values remained within the normal range.

It has been claimed that NGAL is an early biomarker of acute renal injury [32], but NGAL values can vary considerably even in the absence of adverse kidney effects. Using the same test as was used in the two previously mentioned studies, Wagener and colleagues reported rises of 165 to $1,490 \mathrm{ng} / \mathrm{ml}$ in cardiac surgery patients with and without acute kidney injury [33]. These results suggest that values reported by Boldt and colleagues are very low and, although the type of solution significantly influenced the NGAL values, there is no indication of significant impairment in renal function.

In conclusion, no significant differences in creatinine variations have been reported and only slight differences in NGAL, not clinically relevant, were observed. From these results one may conclude there is no convincing difference between isotonic saline strategies and balanced strategies in terms of renal function.

\section{Effects of dilutional-hyperchloraemic acidosis on coagulation and bleeding}

Data from in vitro studies suggest that balanced solutions may have fewer negative effects on coagulation parameters $[34,35]$. The authors acknowledge the inherent problems of in vitro studies, however, which include the effects of haemodilution, calcium dilution and the absence of physiological components such as the endothelium. Owing to these significant limitations, no clinically relevant conclusions can be drawn from in vitro studies.

Clinical studies provide more relevant insights. Boldt and colleagues compared the effects of very high doses (around 18 litres in 48 hours) of Ringer's lactate and isotonic saline in patients undergoing abdominal surgery (Table 3) [16]. There was no significant difference in coagulation tests and in blood loss between the groups.

Waters and colleagues compared Ringer's lactate with isotonic saline in patients undergoing repair of abdominal and thoracoabdominal aortic aneurysm (Table 5) [36]. There was a small but nonsignificant difference in blood loss in favour of the Ringer's lactate group (Table 5). There was no significant difference in the use of packed red blood cells or fresh-frozen plasma between the two groups. The only statistically significant difference was a higher volume of platelet transfusion in the saline group. When all blood products were summed, the use of blood products was significantly higher in the saline group. Both groups included patients with thoracoabdominal aneurysm, however, which may account for the high variability in blood loss and transfusion requirements. No significant difference in morbidity or mortality was reported.

Studies investigating the use of colloids also found no difference in blood loss between colloids in balanced solutions and those in isotonic saline solutions. Kulla and colleagues did not observe differences in blood loss patients undergoing abdominal surgery, and all other coagulation parameters were not significantly different between the two groups [21]. A similar study by Boldt and colleagues also found no difference in blood loss between the two groups (Table 5) [18].

Only one study reported differences between isotonic saline-based and balanced colloids. Comparing HES $130 / 0.42$ in balanced solution with albumin in saline as a priming solution for cardiopulmonary bypass, Boldt and colleagues reported small but significant differences in coagulation (Rotem, Pentapharm, Munich, Germany) in favour of the balanced HES. This observation was associated with significantly lower blood loss [20]. Similarly, use of blood products throughout and after surgery was significantly lower in the HES group (Table 5). The number of patients in each group was very small $(n=25)$, however, given that coagulation and bleeding in cardiac surgery may be highly variable. A recent study performed by the same investigators in the same setting (cardiac surgery), comparing a balanced HES with albumin, did not confirm these results [22].

In conclusion, there is little evidence that large volumes of isotonic saline have a significantly detrimental effect on coagulation, blood loss or transfusion.

\section{Effects of dilutional-hyperchloraemic acidosis on gastrointestinal function}

Several studies have investigated the effects of dilutionalhyperchloraemic acidosis on gastrointestinal function with controversial results.

Williams and colleagues reported that healthy volunteers receiving saline experienced more frequent abdominal discomfort than those receiving Ringer's lactate [15]. Wilkes and colleagues investigated the effects of $6 \%$ hetastarch in a balanced carrier plus Ringer's lactate versus hetastarch in saline plus isotonic saline in elderly surgical patients [37]. The only difference related to gastrointestinal function was a small difference in the gastric $\mathrm{CO}_{2}$ gradient, which showed a larger increase in the saline group. The difference is small and probably not clinically relevant $(0.3 \pm 1.5 \mathrm{kPa}$ in the Ringer's lactate group compared with $1.0 \pm 0.7 \mathrm{kPa}$ in the saline group), but may suggest a better gastric mucosal perfusion in the Ringer's lactate group. A nonsignificant trend towards more nausea and vomiting was observed in the saline group. 
Table 5. Blood loss in studies comparing a balanced strategy with a saline-based strategy

\begin{tabular}{|c|c|c|c|}
\hline Study & Group & Blood loss (ml) & $P$ value between groups \\
\hline \multicolumn{4}{|l|}{ Crystalloids only } \\
\hline \multirow[t]{2}{*}{ Waters and colleagues [36] } & Ringer's lactate & $2,300(1,600$ to 3,500$)$ & NS \\
\hline & Isotonic saline & $2,900(1,930$ to 4,000$)$ & \\
\hline \multirow[t]{2}{*}{ Boldt and colleagues [16] } & Ringer's lactate & $1,830 \pm 380$ & NS \\
\hline & Isotonic saline & $1,730 \pm 390$ & \\
\hline \multicolumn{4}{|l|}{ Colloids and crystalloids } \\
\hline \multirow[t]{2}{*}{ Kulla and colleagues [21] } & HES 130/0.42 + Ringer's acetate & $1,156 \pm 917$ & NS \\
\hline & HES 130/0.42 + modified saline & $1,228 \pm 691$ & \\
\hline \multirow[t]{2}{*}{ Boldt and colleagues [18] } & HES 130/0.42 + modified RL & $1,798 \pm 1,220$ & NS \\
\hline & HES 130/0.42 + isotonic saline & $1,557 \pm 1,165$ & \\
\hline \multirow[t]{2}{*}{ Boldt and colleagues [19] } & HES 130/0.42 + modified RL & $1,510 \pm 410$ & NS \\
\hline & HES 130/0.42 + isotonic saline & $1,380 \pm 460$ & \\
\hline \multirow[t]{2}{*}{ Boldt and colleagues [20] } & HES 130/0.42 + modified RL & $1,200 \pm 290$ & $<0.05$ \\
\hline & Albumin $5 \%+$ isotonic saline & $1,520 \pm 210$ & \\
\hline \multirow[t]{2}{*}{ Boldt and colleagues [22] } & HES 130/0.40 + modified RL & $1,380 \pm 460$ & NS \\
\hline & Albumin $5 \%+$ isotonic saline & $1,510 \pm 410$ & \\
\hline
\end{tabular}

HES, hydroxyethyl starch; RL, Ringer's lactate.

Moretti and colleagues reported different results. Patients were randomised into three groups to compare the effects of hetastarch in isotonic saline, of hetastarch in balanced solution and of Ringer's lactate on postoperative outcomes [38]. While there was no significant difference in the incidence of nausea and use of antiemetics between the hetastarch groups, both were significantly lower than in the Ringer's lactate group (Table 6). The authors concluded that intraoperative fluid resuscitation with colloids, compared with crystalloids, improved postoperative recovery with regards to postoperative nausea and vomiting. These results suggest that fluid volume may be more important than composition. Several other studies suggest that intraoperative crystalloid restriction may be associated with an improvement in gastrointestinal function and a decrease in postoperative complications [39-41].

In conclusion, there is not sufficient evidence from the available literature to suggest that dilutional-hyperchloraemic acidosis has a clinically relevant effect on gastrointestinal function. Some degree of intraoperative crystalloid restriction and colloid use may, however, be associated with an improvement in gastrointestinal function and outcome.

Effects of dilutional-hyperchloraemic acidosis on mortality Metabolic acidosis is often associated with adverse outcomes; however, it is important to differentiate between the effects of acidosis itself and the conditions that cause it. In the clinical setting, metabolic acidosis arises from different causes, within which hyperchloraemia may play a role. Following trauma, for example, major metabolic acidosis has been reported in relation to severe hypovolaemia, tissue hypoxia and shock. In this situation, it is very difficult to determine the specific role of isotonic saline administration and the potential impact of other mechanisms on outcome [42-45].

Experimental studies may therefore be useful to understand the impact of fluid therapy on outcome. Short-term survival was measured in a model of experimental sepsis with rats resuscitated with a balanced hetastarch, Ringer's lactate or isotonic saline [46]. In terms of mortality, Ringer's lactate was no better than isotonic saline. The best survival was observed in the colloid group, suggesting that a colloid strategy may be favourable in sepsis.

Gunnerson and colleagues carried out an observational, retrospective review of hospital data of 9,799 critically ill patients admitted to the intensive care unit [47]. They selected a cohort $(n=851)$ in which clinicians ordered a measurement of arterial lactate level; 584 patients (64\%) had a metabolic acidosis, either related to lactate, a strong ion gap or hyperchloraemia. Mortality was highest in patients with lactate acidosis (56\%). In patients with dilutional-hyperchloraemic acidosis, mortality was the same as in the control group without metabolic acidosis (Figure 4). From this observational study, it may be concluded that patients with hyperchloraemic acidosis were not associated with an increased risk of mortality compared with critically ill patients without metabolic acidosis. 
Table 6. Incidence and severity of postoperative complications [38]

\begin{tabular}{lcccc}
\hline Variable & $\mathbf{6 \%}$ hetastarch in saline & $\mathbf{6 \%}$ hetastarch in balanced salt & Ringer's lactate & $\boldsymbol{P}$ value \\
\hline Nausea & $14(47 \%)$ & $11(37 \%)$ & $22(73 \%)$ & \\
Nausea severity & 8 & & 4 & 0.007 \\
$\quad 1$ (mild) & 4 & 2 & 10 & 0.02 \\
2 (moderate) & 2 & 4 & 8 & $16(53 \%)$ \\
$\quad 3$ (severe) & $8(27 \%)$ & 5 & $18(60 \%)$ & 0.02 \\
Emesis & $9(30 \%)$ & $7(23 \%)$ & & 0.006 \\
Rescue antiemetic & & $8(27 \%)$ & &
\end{tabular}

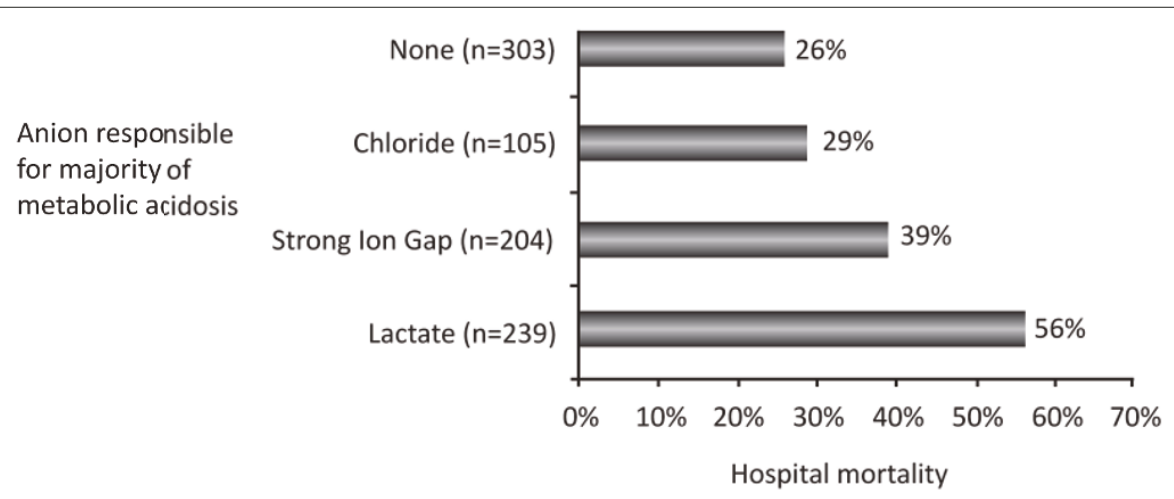

Figure 4. Hospital mortality associated with type of metabolic acidosis. Mortality associated with the major ion contributing to the metabolic acidosis. Hospital mortality associated with the various causes of metabolic acidosis (standard base excess (SBE) $<-2$ ). Mortality percentage is mortality within each subgroup, not a percentage of overall mortality. Lactate indicates that lactate contributes to at least 50\% of the SBE; SIG, strong ion gap contributes to at least 50\% of SBE (and not lactate); hyperchloraemic, absence of lactate or SIG acidosis and SBE <-2; none, no metabolic acidosis (SBE $\geq-2 \mathrm{mEq} / \mathrm{l}) . P<0.001$ for the four-group comparison. Adapted from Gunnerson and colleagues [47].

Noritomi and colleagues performed an observational study in 60 patients with severe sepsis and septic shock [48]. In this group of patients, mortality was significantly associated with an increased inorganic ion difference. The difference in plasma chloride concentrations between survivors and nonsurvivors was minimal ( $3 \mathrm{mEq} / \mathrm{l})$. Of note in the Rivers study, a difference in base excess of $5 \mathrm{mEq} / \mathrm{l}$ after 6 hours of treatment was observed between optimised patients and controls, with a concomitant reduced mortality in the patients receiving the highest dose of colloids and crystalloids (6 litres versus 4.5 litres) [49]. In their study, however, several confounding variables might have influenced the acid-base status and the mortality is more related to the cause of acidosis rather than to transient dilutional-hyperchloraemic acidosis.

In a prospective observational study set in the paediatric intensive care unit following cardiac surgery, Hatherill and colleagues documented that dilutionalhyperchloraemic acidosis was associated with reduced requirement for adrenaline therapy [50]. It is suggested that dilutional-hyperchloraemic acidosis is a benign phenomenon that should not prompt escalation of haemodynamic support.
In another prospective observational trial, Brill and colleagues studied 75 consecutive surgical intensive care patients with base deficits $>2.0 \mathrm{mmol} / \mathrm{l}$. Patients were divided into those with hyperchloraemic acidosis and those with acidosis from other causes. There were no significant differences in age, Acute Physiology and Chronic Health Evaluation II scores, or volumes of resuscitation between the hyperchloraemic group and the remaining patients. There were four deaths $(10.8 \%)$ in the hyperchloraemic group and 13 deaths $(34.2 \%)$ in the remaining patients $(P=0.03)$. The authors concluded that hyperchloraemic acidosis is a common cause of base deficit in the surgical intensive care unit, associated with lower mortality than base deficit secondary to another cause [51]. Maciel and Park have reported similar results [52].

\section{Conclusion}

The current review has presented an extensive analysis of all available studies using balanced solutions. We conclude that dilutional-hyperchloraemic acidosis is a side effect, mainly observed after the administration of large volumes of isotonic saline as a crystalloid. In this particular setting, however, the effect remains moderate 
and relatively transient ( 24 to 48 hours), and is minimised with the use of olloids, whatever the nature of the carrier. From the available literature, the evidence for adverse effects of dilutional-hyperchloraemic acidosis on organ function, morbidity or mortality remains of small importance. In addition, the use of colloids together with crystalloids allows a reduction of the total volume of fluids used and considerably limits the chloride load.

In view of the substantial experimental and clinical information on the efficacy and safety of various colloids, including third-generation HES (HES 130/0.4), and of the limited published information on the effects of balanced solutions on outcome, we cannot changing to a new generation of colloids until there is evidence suggesting genuine detriment from existing fluids and clear evidence of benefit with new solutions.

\section{Key messages}

- The term dilutional-hyperchloraemic accurately defines a decrease in base excess, or a decrease in SID, associated with hyperchloraemia and a normal anion gap.

- Isotonic saline describes the main property of $0.9 \%$ saline solution. It is neither normal, abnormal nor unbalanced. Balanced solutions is a general term to describe different solutions with different electrolyte compositions.

- Dilutional-hyperchloraemic acidosis is a moderate and relatively transient side effect, minimised or avoided by limiting crystalloid administration through the use of colloids in any carrier.

- No convincing evidence for clinically relevant adverse effects of dilutional-hyperchloraemic acidosis on morbidity or mortality can be found.

- Following extensive review, owing to the limited published information on the effects of balanced solutions on outcome, the change of practice from colloids in isotonic saline to balanced colloid use cannot be recommended.

\footnotetext{
Abbreviations

$A_{\text {tot' }}$ sum of all anionic charges of weak plasma acids; $\mathrm{CO}_{2}$, carbon dioxide; HES, hydroxyethyl starch; NGAL, neutrophil gelatinase-associated lipocalin; $\mathrm{PCO}_{2}$ partial pressure of carbon dioxide; SID, strong ion difference.

\section{Competing interests}

BG has received honoraria and financial reimbursements from Fresenius Kabi for lecturing and authorship, and from Laboratoire Français du Fractionnement et des Biotechnologies for lecturing; he is the principal clinical trial investigator in the Effects of Voluven on Hemodynamics and Tolerability of Enteral Nutrition in Patients With Severe Sepsis (CRYSTMAS Trial), sponsored by Fresenius Kabi. NS has received honoraria and financial reimbursements from Fresenius Kabi; his nonfinancial competing interest pertains to adverse comments made about a set of guidelines relating to fluids, both in lectures and in text. GDR has received honoraria for attending a Fresenius Kabi advisory board meeting. SK has received honoraria for lecturing, and reimbursements for travel and hotel accommodation from Fresenius Kabi and B Braun. BV has received consulting fees and honoraria from B Braun, Baxter and Fresenius Kabi. DA has received honoraria for attending a Fresenius Kabi advisory board meeting. MJ has received honoraria for lectures from several fluid companies,
}

particularly Fresenius Kabi; he was given an unrestricted educational grant from Fresenius Kabi for the First Randomised Controlled, Double-blind Study of Crystalloids vs Colloids in Trauma (FIRST Trial).

\section{Acknowledgements}

The present work was supported by an unrestricted educational grant from Fresenius Kabi.

\section{Author details}

'Inserm, Unité de Recherche en Épidémiologie Systèmes d'Information et Modélisation (U707), Paris F-75012, France. 'UPMC Université, Paris 06, 4 Place Jussieu, 75005 Paris, France. ${ }^{3}$ Medical ICU, Assistance Publique Hôpitaux de Paris, Hôpital Saint-Antoine, Service de Réanimation Médicale, Paris F-75012, France. ${ }^{4}$ Intensive Care and Anaesthesia, Chelsea and Westminster Hospital, London SW10 9NH, UK. ${ }^{5}$ mperial College London, Division of Surgery, Oncology, Reproductive Biology and Anaesthetics, South Kensington Campus, London SW7 2AZ, UK. 'Department of Anesthesia and Intensive Care Medicine, University Hospital, Medical School, University of Udine, P.le S. Maria della Misericordia, 1533100 Udine, Italy. ${ }^{7}$ Department of Anaesthesiology, General Intensive Care and Pain Management, Vienna Medical University, Waehringer Guertel 18-20, 1090 Vienna, Austria.

${ }^{8}$ Department of Anesthesiology and Critical Care Medicine, Pôle d'Anesthesie Reanimation, Hôpital Claude Huriez, rue Michel Polonoski, CHU Univ Nord de France, 59000 Lille, France. ${ }^{9} \mathrm{Cr}$ itical Care Department, Service Reanimation Medicale, Hôpital Raymond Poincaré (Assistance Publique - Hôpitaux de Paris), Université de Versailles SQY, 104 bd Raymond Poincaré, 92380 Garches, France. ${ }^{10}$ Department of Anaesthesia, University of Cape Town, Anzio Road, Observatory 7925, Cape Town, South Africa.

Published: 21 October 2010

\section{References}

1. Powell-Tuck J, Gosling P, Lobo DN, Allison SP, Carlson GL, Gore M, Lewington AJ, Pearse RM, Mythen MG: British Consensus Guidelines on Intravenous Fluid Therapy for Adult Surgical Patients (GIFTASUP). London: NHS National Library of Health; 2009.

2. Liu B, Finfer S: Intravenous fluids in adults undergoing surgery [editorial]. BrMed J 2009, 339:3-4.

3. Handy JM, Soni N: Physiological effects of hyperchloraemia and acidosis. Br J Anaesth 2008, 101:141-150.

4. Shaneyfelt TM, Centor RM: Reassessment of clinical practice guidelines: go gently into that good night. JAMA 2009, 301:868-869.

5. Hasselbalch KA: Die berechnung der wasserstoffzahl des blutes auf der freien und gebundenen kohlensaure desselben, und die sauerstoffbindung des blutes als funktion der wasserstoffzahl. Biochem Z 1916, 78:112-144.

6. Stewart PA: Modern quantitative acid-base chemistry. Can J Physiol Pharmacol 1983, 61:1444-1461.

7. Yunos NM, Bellomo R, Story D, Kellum J: Bench-to-bedside review: chloride in critical illness. Crit Care 2010, 14:226.

8. Constable PD: Hyperchloremic acidosis: the classic example of strong ion acidosis. Anesth Analg 2003, 96:919-922.

9. Morgan TJ, Venkatesh B: Designing 'balanced' crystalloids. Crit Care ResusC 2003, 5:284-291.

10. Doberer D, Funk G-C, Kirchner K, Schneeweiss B: A critique of Stewart's approach: the chemical mechanism of dilutional acidosis. Intensive Care Med 2009, 35:2173-2180.

11. Kurtz I, Kraut J, Ornekian V, Nguyen MK: Acid-base analysis: a critique of the Stewart and bicarbonate-centered approaches. Am J Physiol Renal Physiol 2008, 294:F1009-F1031.

12. Lang W, Zander R: Prediction of dilutional acidosis based on the revised classical dilution concept for bicarbonate. J Apply Physiol 2005, 98:62-71.

13. Rehm M, Finsterer U: Treating intraoperative hyperchloremic acidosis with sodium bicarbonate or tris-hydroxymethyl aminomethane: a randomized prospective study. Anesth Analg 2003, 96:1201-1208.

14. Scheingraber S, Rehm M, Sehmisch C, Finsterer U: Rapid saline infusion produces hyperchloremic acidosis in patients undergoing gynaecologic surgery. Anesthesiol 1999, 90:1265-1270.

15. Williams EL, Hildebrand KL, McCormick SA, Bedel MJ: The effect of intravenous lactated Ringer's solution versus $0.9 \%$ sodium chloride solution on serum osmolality in human volunteers. Anesth Analg 1999, 
88:999-1003.

16. Boldt J, Haisch G, Suttner S, Kumle B, Schellhase F: Are lactated Ringer's solution and normal saline solution equal with regard to coagulation? Anesth Analg 2002, 94:378-384.

17. Base E, Standl T, Mahl C, Jungheinrich C: Comparison of $6 \%$ HES 130/0.4 in a balanced electrolyte solution versus 6\% HES 130/0.4 in saline solution in cardiac surgery [abstract]. Crit Care 2006, 10:176.

18. Boldt J, Schöllhorn T, Münchbach J, Pabsdorf M: A total balanced volume replacement strategy using a new balanced hydroxyethyl starch preparation (6\% HES 130/0.42) in patients undergoing major abdominal surgery. Eur J Anaesthesiol 2007, 24:267-275.

19. Boldt J, Suttner S, Brosch C, Lehmann A, Roehm K, Mengistu A: The influence of a balanced volume replacement concept on inflammation, endothelial activation, and kidney integrity in elderly cardiac surgery patients. Intensive Care Med 2009, 35:462-470.

20. Boldt J, Suttner S, Brosch C, Lehmann A, Roehm K, Mengistu A: Cardiopulmonary bypass priming using a high dose of a balanced hydroxyethyl starch versus an albumin-based priming strategy. Anesth Analg 2009, 109:1752-1762.

21. Kulla M, Weidhase R, Lampl L: Hydroxyethyl starch 6\% 130/0.42 in acetatebuffered Ringer's solution as a part of a balanced-volume resuscitation in abdominal surgery. Anasth Intensivmed 2008, 49:7-18.

22. Boldt J, Mayer J, Brosch C, Lehmann A, Mengistu A: Volume replacement with a balanced hydroxyethyl starch (HES) preparation in cardiac surgery patients. J Cardiothorac Vasc Anesth 2010, 24:399-407.

23. O'Dell E, Tibby SM, Durward A, Murdoch IA: Hyperchloremia is the dominant cause of metabolic acidosis in the postresuscitation phase of pediatric meningococcal sepsis. Crit Care Med 2007, 35:2390-2394.

24. Boldt J, Ducke M, Kumle B, Papsdorf M, Surmeyer EL: Influence of different volume replacement strategies on inflammation and endothelial activation in the elderly undergoing major abdominal surgery. Intensive Care Med 2004, 30:416-422

25. Kotchen TA, Luke RG, Ott CE, Galla JH, Whitescarver W: Effect of chloride on renin and blood pressure responses to sodium chloride. Ann Intern Med 1983, 98:817-822

26. Wilcox CS: Regulation of renal blood flow by plasma chloride. J Clin Invest 1983, 71:726-735.

27. Wilcox CS, Peart WS: Release of renin and angiotensin II into plasma and lymph during hyperchloremia. Am J Physiol 1987, 4:734-741.

28. Quilley CP, Lin Y-S, McGiff JC: Chloride anion concentration as a determinant of renal vascular responsiveness to vasoconstrictor agents. Br J Pharmacol 1993, 108:106-110.

29. Hansen PB, Jensen BL, Skott O: Chloride regulates afferent arteriolar contraction in response to depolarization. Hypertension 1998 32:1066-1070

30. Reid F, Lobo DN, Williams RN, Rowlands BJ, Allison SP: (Ab)normal saline and physiological Hartmann's solution: a randomized double-blind crossover study. Clin Sci 2003, 104:17-24.

31. O'Malley CM, Frumento RJ, Hardy MA, Benvenisty Al, Brentjens TE, Mercer JS, Bennett-Guerrero, E: A randomized, double-blind comparison of lactated Ringer's solution and $0.9 \% \mathrm{NaCl}$ during renal transplantation. Anesth Analg 2005, 100:1518-1524.

32. Bennett M, Dent CL, Ma Q Dastrala S, Grenier F, Workman R, Syed, Ali S, Barasch J, Devarajan P: Urine NGAL predicts severity of acute kidney injury after cardiac surgery: a prospective study. Clin J Am Soc Nephrol 2008, 3:665-673.

33. Wagener G, Gubitosa G, Wang S, Borregaard N, Kim M, Lee HT: Urinary neutrophil gelatinase-associated lipocalin and acute kidney injury after cardiac surgery. Am J Kidney Dis 2008, 52:425-433.

34. Boldt J, Wolf $\mathrm{M}$, Mengistu A: A new plasma-adapted hydroxyethylstarch preparation: in vitro coagulation studies using thrombelastography and whole blood aggregometry. Anesth Analg 2007, 104:425-430

35. Boldt J, Mengistu A, Seyfert U, Vogt A, Hellstern P: The impact of a medium molecular weight, low molar substitution hydroxyethyl starch dissolved in a physiologically balanced electrolyte solution on blood coagulation and platelet function in vitro. Vox Sang 2007, 93:139-144.
36. Waters JH, Gottlieb A, Schoenwald P, Popovich MJ, Sprung J, Nelson DR: Normal saline versus lactated Ringer's solution for intraoperative fluid management in patients undergoing abdominal aortic aneurysm repair: an outcome study. Anesth Analg 2001, 93:817-822.

37. Wilkes NJ, Woolf R, Mutch M, Mallett SV, Peachey T, Stephens R, Mythen MG: The effects of balanced versus saline-based hetastarch and crystalloid solutions on acid-base and electrolyte status and gastric mucosal perfusion in elderly surgical patients. Anesth Analg 2001, 93:811-816.

38. Moretti EW, Robertson KM, el-Moalem H, Gan TJ: Intraoperative colloid administration reduces postoperative nausea and vomiting and improves postoperative outcomes compared with crystalloid administration. Anesth Analg 2003, 96:611-617.

39. Lobo DN, Bostock KA, Neal KR, Perkins AC, Rowlands BJ, Allison SP: Effect of salt and water balance on recovery of gastrointestinal function after elective colonic resection: a randomised controlled trial. Lancet 2002, 359:1812-1818.

40. Nisanevich V, Felsenstein I, Almogy G, Weissman C, Einay S, Matot I: Effect of intraoperative fluid management on outcome after intra-abdominal surgery. Anesthesiology 2005, 103:25-32.

41. Brandstrup B, Tonnesen E, Beier-Holgersen R, Hjortso E, Ording H, LindorffLarsen K, Rasmussen MS, Lanng C, Wallin L, Iversen LH, Gramkow CS, Okholm M, Blemmer T, Svendsen PE, Rottensten HH, Thage B, Rils J, Jeppesen IS, Teilum D, Christensen AM, Graungaard B, Pott F: Effects of intravenous fluid restriction on postoperative complications: comparison of two perioperative fluid regimens: a randomized assessor-blinded multicenter trial. Ann Surg 2003, 238:641-648.

42. Siegel JH, Rivkind Al, Dalal S, Goodarzi S: Early physiologic predictors of injury severity and death in blunt multiple trauma. Arch Surg 1990, 125:498-508

43. Rixen D, Raum M, Bouillon B, Lefering R, Neugebauer E: Base deficit development and its prognostic significance in posttrauma critical illness: an analysis by the trauma registry of the Deutsche Gesellschaft fur Unfallchirurgie. Shock 2001, 15:83-89.

44. Rutherford EJ, Morris JA, Reed GW, Hall KS: Base deficit stratifies mortality and determines therapy. J Trauma 1992, 33:417-423.

45. Davis JW, Parks SN, Kaups KL, Gladen HE, O'Donnel-Nicol S: Admission base deficit predicts transfusion requirements and risk of complications. J Trauma 1996, 41:769-774.

46. Kellum JA: Fluid resuscitation and hyperchloremic acidosis in experimental sepsis: improved short-term survival and acid-base balance with Hextend compared with saline. Crit Care Med 2002, 30:300-305

47. Gunnerson KJ, Saul M, He S, Kellum JA: Lactate versus non-lactate metabolic acidosis: a retrospective outcome evaluation of critically ill patients. Crit Care 2006, 10:R22.

48. Noritomi DT, Soriano FG, Kellum JA, Cappi SB, Biselli PJC, Liborio AB, Park M: Metabolic acidosis in patients with severe sepsis and septic shock: a longitudinal quantitative study. Crit Care Med 2009, 37:1-7.

49. Rivers E, Nguyen B, Havstad S, Ressler J, Muzzin A, Knoblich B, Peterson E, Tomlanovich M: Early goal-directed therapy in the treatment of severe sepsis and septic shock. N Eng/ J Med 2001, 345:1368-1377.

50. Hatherill M, Salie S, Waggie Z, Lawrenson J, Hewitson J, Reynolds L, Argent A. Hyperchloraemic metabolic acidosis following open cardiac surgery. Arch Dis Child 2005, 90:1288-1292.

51. Brill SA, Stewart TW, Brundage SI, Schreiber MA. Base deficit does not predict mortality when secondary to hyperchloremic acidosis. Shock 2002, 17:459-462.

52. Maciel AT, Park M: Differences in acid-base behavior between intensive care unit survivors and nonsurvivors using both a physicochemical and a standard base excess approach: a prospective, observational study. J Crit Care 2009, 24:477-483.

doi:10.1186/cc9230

Cite this article as: Guidet B, et al:: A balanced view of balanced solutions. Critical Care 2010, 14:325. 